\title{
A produção escrita de pessoas com deficiência intelectual na interação com as tecnologias digitais da informação e comunicação
}

\author{
Flávia Roldan Viana* \\ Adriana Leite Limaverde Gomes**
}

\section{Resumo}

Este artigo se insere em uma pesquisa maior, que investiga se a mediação em contexto digital exerce influência sobre a qualidade das produçóes textuais, sob os aspectos semânticos e ortográficos da escrita de pessoas com deficiência intelectual (DI). O estudo maior também verifica se a atividade de alimentação de Blogs exerce influência sobre a interaçâo social, as Tecnologias Digitais de Informação e Comunicaçâo (TDIC) e o letramento digital. A investigação se respalda na abordagem socioconstrutivista. Neste texto, objetiva-se investigar se a utilização das TDIC, em pareceria com os mediadores voluntários (MV), influencia o desenvolvimento das competências de escrita de pessoas com DI. A coleta de dados realiza-se mediante a proposição de sessôes de intervenção, nas quais as pessoas com DI produzem textos, sob a mediação dos MV, no contexto digital. Os resultados indicam que as estratégias de mediação estabelecidas pelo MV exercem influência positiva sobre as competências de escrita dos participantes com DI, visto que eles alteram qualitativamente seus textos. Esse resultado sugere que a mediação do MV no contexto digital se constitui como uma estratégia importante por possibilitar evolução da produção escrita de pessoas com DI. Conclui-se que os participantes desta investigação se beneficiam das TDIC, e demonstram competência para utilizar os recursos disponíveis no meio digital. A evolução da escrita se comprova, quando as açôes das pessoas com DI no uso das TDIC são mediadas de forma clara, contextualizada, objetiva e adequada.

Palavras-chaves: Tecnologias digitais da informação e comunicação; Produção escrita; Deficiência intelectual.

* Professora doutora da Universidade Federal do Rio Grande do Norte, Natal, Rio Grande do Norte, Brasil.

** Professora doutora da Universidade Federal do Ceará, Benfica, Fortaleza, Ceará. 


\title{
Production writing intellectual disability in interaction with digital technologies of information and communication
}

\begin{abstract}
This article is part of a larger research that investigates whether mediation in the digital environment influences the quality of textual productions under the semantic and orthographic writing of people with intellectual disabilities (DI). The largest study also verifies that the Blogs feeding activity influences the social interaction, Digital Technologies of Information and Communication (TDIC) and digital literacy. The research supports the socio-constructivist approach. This paper aims to investigate the use of TDIC, in partnership with volunteer mediators (MV), influences the development of writing skills of people with DI. Data collection is performed by the proposition of intervention sessions in which people with DI produce texts, under the mediation of the MV in the digital context. The results indicate that the mediation strategies established by MV exert positive influence on the writing skills of participants with DI, as they qualitatively change their texts. This result suggests that the mediation of the MV in the digital environment is constituted as an important strategy for enabling evolution from the writing of people with DI. We conclude that the participants of this research benefit from TDIC, and demonstrate competence to use the resources available in the digital environment. The evolution of writing is verified, when the actions of people with ID in the use of TDIC are mediated clearly, contextualized, objective and adequate.
\end{abstract}

Keywords: Information and communication digital technologies; Written production; Intellectual disability.

\section{Introdução}

Este trabalho pauta-se na perspectiva sócio-construtivista, e insere-se em uma pesquisa maior de iniciação científica, coordenada pelo grupo de pesquisa LER Linguagem Escrita Revisitada - do Programa de Pós-Graduação em Educação da Universidade Federal do Ceará (UFC). A pesquisa maior investiga se a mediação em contexto digital exerce influência sobre a qualidade das produçôes textuais, sob os aspectos semânticos e ortográficos da escrita de pessoas com Deficiência Intelectual (DI). Este estudo também verifica se a atividade de alimentação de Blogs exerce influência sobre a interação social, as Tecnologias Digitais de Informação e Comunicação (TDIC) e o letramento digital.

No presente texto, objetiva-se investigar se a utilização das TDIC, em parceria com mediadores voluntários (MV), influencia o desenvolvimento das competências de escrita de pessoas com DI em contexto digital. Pretende-se investigar, particularmente, as competências de escrita dessas pessoas durante as produçôes mediadas.

Participam deste estudo cinco pessoas com DI e três MV, esses últimos são estudantes do curso de Pedagogia da UFC. Os participantes com DI são identifi- 
cados como P1, P2, P3, P4 e P5, para preservar suas identidades. A metodologia desenvolve-se por meio da realizaçáo de um total de 15 sessóes para cada pessoa com DI. As sessóes consistem na construção e no desenvolvimento de um Blog por cada participante com deficiência intelectual. As sessóes ocorrem na frequência de uma vez por semana, nas quais as pessoas com DI alimentam seus Blogs em parceira com o MV. Neste artigo são apresentados os dados de três sessões (SE4, SE9 e SE15). A SE4 considerada inicial, a sessão 4, intermediária, a sessão 9, e a SE15, a final.

No desenvolvimento da pesquisa, cada participante com DI cria e desenvolve um Blog de temáticas variadas, que são escolhidas livremente por eles. As temáticas versam sobre gostos musicais e eventos familiares, assuntos relativos à juventude, viagens e lugares de lazer. Eles também abordam assuntos sobre o cotidiano e as atividades culturais, assim como as preferências pessoais de músicas e de poesias.

No âmbito da pesquisa maior definem-se oito categorias: Leitura, Aspectos Ortográficos da Escrita, Aspectos Semânticos da Escrita, Estratégias Cognitivas, Interação com o Computador, Interação com as TDIC, Letramento Digital, Interação Social.

A realização deste artigo compreende os resultados agrupados na categoria Interação com as TDIC. Esta categoria define-se como toda forma de interação ou comunicação com as TDIC. Isto é, tudo que se busca na internet é um tipo de interação com as TDIC. Nessa categoria, identificam-se vinte comportamentos das pessoas com DI. Esses comportamentos são organizados em níveis evolutivos e classificados como elementares (N1), intermediários (N2) e avançados (N3), de acordo com as características de sua ocorrência. Esses níveis são detalhados na análise dos dados.

A pesquisa justifica-se, tendo em vista que a internet é um meio eletrônico que favorece a leitura e a escrita de diversos gêneros discursivos, assim como de novos gêneros discursivos emergentes (MARCUSCHI 2010). Conforme aponta Murano (2011, p. 33), "com os recursos de interação cada vez mais expandidos, qualquer site é um convite a comentários, críticas e observaçóes, obrigando os internautas a desenvolverem discursos de improviso e a defender seus pontos de vista". Dessa forma, as possibilidades de leitura e escrita franqueadas pelo contexto digital se constitui um convite aos internautas para a produção de textos de modo interativo, dinâmico e significativo.

\section{Considerações Teóricas - a pessoa com deficiência intelectual e o uso das tecnologias digitais da informação e comunicação em contexto de mediação}

A concepção de deficiência intelectual modificou-se historicamente passando a ser compreendida não como doença ou patologia, mas como condiçấo de saúde, que afeta as estruturas e funçóes do corpo, atividade, participação, passando "a ser entendida num contínuo de situaçóes provocadas pelas relaçôes estabelecidas entre as diferentes variáveis envolvidas" (SANCHES-FERREIRA; LOPES-DOS-SANTOS e SANTOS, 2012, p. 562). 
As pessoas com deficiência intelectual apresentam um ritmo de desenvolvimento mais lento quanto comparado às pessoas sem esse tipo de deficiência. Elas também se diferenciam pela dificuldade de alcançarem o nível final das operaçôes mentais espontaneamente e, sobretudo, pela dificuldade de mobilizar os conhecimentos prévios para solucionar problemas (GOMES; POULIN; FIGUEIREDO, 2010; OMS, 2007).

Estudos realizados por diversos pesquisadores (FIGUEIREDO, 2008; FIGUEIREDO e FERNANDES, 2009; GIROTO, POKER e OMOTE, 2012; ROCHA, ALVES e NEVES, 2004; SANTAROSA, 2002) apontam que mediante uma intervenção pedagógica, em contextos mediados, as pessoas com deficiência intelectual têm a capacidade de construir e fomentar os instrumentos cognitivos necessários à aquisição dos esquemas das operaçôes concretas. Para esses autores, essa aquisição só é possível desde que essas pessoas sejam estimuladas, de forma sistemática, e adequada, às suas necessidades metacognitivas1. "É importante considerar a mediação como um fenômeno multifacetado, visto que nela estáo implicados diversos aspectos do desenvolvimento e não apenas os processos cognitivos" (GOMES; POULIN; FIGUEIREDO, 2010, p. 15). Nesse contexto, torna-se necessário nos momentos de aprendizagem, a promoção de oportunidades mediadas e de interaçáo, para que seja proporcionado um ambiente de ensino e aprendizagem, que atenda as especificidades desse alunado. Para Friend e Bursuck (1999), para atender a essa peculiaridade é preciso desenvolver estratégias diferenciadas de ensino, propostas avaliativas e atividades acessíveis. $\mathrm{O}$ atendimento a esses aspectos apontados por esses autores demanda novas perspectivas teóricas e um novo olhar sobre a pessoa com deficiência intelectual, sobrepondo à visão da incompetência intelectual, marca dos estigmas do ensino tradicional.

Dessa forma, pode-se inferir que o contexto digital se apresenta como uma estratégia diferenciada no contexto do desenvolvimento da linguagem escrita, na medida em que possibilita diferentes formas de interação com a linguagem textual e se torna um mediador de novas práticas de leitura e escrita como apontam Cereja e Magalhães (2008):

\footnotetext{
$\mathrm{Na}$ internet o processo de ler ou escrever um texto deixou de ser linear, ou seja, da esquerda para a direita e de cima para baixo, um procedimento de cada vez. O internauta pode, simultaneamente ao processo de leitura de um texto, acessar links, ler outros textos, ouvir música, examinar imagens e planilhas, redigir e - mails e, finalmente, voltar a ler o texto que foi o ponto de partida para uma série de operaçôes e de interaçôes pela Internet. (CEREJA; MAGALHÃES, 2008, p. 201).
}

Nessa perspectiva, o desenvolvimento das TDIC se constitui um recurso importante por contribuir para a aprendizagem de pessoas com deficiência intelectual, pois favorece a construção de infinitas possibilidades de acessibilidade ao conhecimento (GIROTO, POKER, OMOTE, 2012). Ainda para os autores, a aplicaçáo das TDIC apresenta inúmeras vantagens para essas pessoas, tais como o respeito ao ritmo e o tempo de cada aluno, a permanência de uma mesma atividade, segundo as possibilidades de elaboração do aluno, a motivação e a promoção da autonomia. 
Segundo Delville, Mercier e Mattys (1999) o uso das tecnologias no campo das deficiências se realiza em diversos setores de aplicação, como no auxílio à comunicação, à vida cotidiana, ao aprendizado e ao desenvolvimento cognitivo. $\mathrm{O}$ uso das tecnologias é um instrumento valioso para que esse alunado aprenda melhor e desenvolva suas potencialidades.

Dessa forma, o uso do blog pode ser um aliado importante no desenvolvimento da linguagem escrita por pessoas com deficiência intelectual, uma vez que, contribui para o desenvolvimento do letramento digital do estudante. O blog também pode contribuir para incentivar a escrita de gêneros textuais diversos no contexto digital. Para Silva e Pessanha (2012) o blog é

\begin{abstract}
Também conhecido como weblog ou diário virtual, o Blog é uma ferramenta bastante dinâmica, em que as pessoas podem publicar diariamente ou periodicamente seus textos na internet, além de links, fotos, músicas e vídeos, que são exibidos sempre da mais recente postagem para a mais antiga. Os textos postados são sempre acompanhados por uma janela para que os leitores possam fazer seus comentários a respeito. (SILVA; PESSANHA, 2012, p. 09).
\end{abstract}

Assim sendo, o blog pode ser considerado uma página da web, na qual o criador ou administrador escreve textos, posta fotos, insere animaçóes, arquivos de som, vídeos dentre outros. No blog, o administrador também cola links relacionados a fatos que ocorrem de forma simultânea. Sua utilização pode permitir uma atualização frequente, e todas as postagens são organizadas automaticamente seguindo a ordem cronológica (Komesu, 2005). A autora acrescenta ainda que há diferentes definiçóes para os variados tipos de blogs, como, por exemplo, blogs pessoais, coletivos, jornalísticos, educacionais dentre outros. Na presente pesquisa, os participantes com DI criam e alimentam blogs pessoais, e estes são desenvolvidos de modo individual, sob a mediação dos MV.

Nesta pesquisa, apesar da variedade das temáticas individuais dos blogs produzidos e desenvolvidos pelos participantes com DI, eles são classificados como blog pessoal. Para Komesu (2005), o blog pessoal apresenta postagens, predominante sobre a esfera íntima da vida do (s) escrevente (s). Este tipo de blog pode ser identificado a partir da ênfase que se dá a assuntos do cotidiano - às atividades diárias, relacionamento interpessoal - com quem o (s) enunciador (es) conversou (aram), se encontrou (aram) - com relatos embasados pela discussão de questôes existenciais que envolvem a vida, o relacionamento afetivo, a família, os amigos, as memórias e os projetos.

De acordo com Primo e Recuero (2003), há ferramentas próprias para a constituição formal dos blogs. A primeira é a ferramenta de comentários, que permite que qualquer um que acesse um blog deixe seu comentário sobre os posts deixados pelo autor. A segunda é a ferramenta trackback que permite que outros posts, em outros blogs, que fizeram referência a um texto deste blog sejam linkados junto dele. Essa segunda ferramenta tem o propósito de mostrar aos internautas a discussão que está acontecendo com relação a um assunto também identificado em outros blogs. Para os autores são exatamente essas ferramentas que fazem do blog um sistema que traz uma organização diferenciada para a web. 
Compreende-se, então, que o uso do Blog em contexto de mediação pode favorecer estimular e impulsionar a capacidade de aprendizagem de pessoas com deficiência intelectual. De acordo com Gomes, Poulin e Figueiredo (2010), pessoas com deficiência intelectual podem apresentar avanços na "capacidade intelectual" em diferentes momentos do processo de aprendizagem que não devem ser compreendidas como de caráter fixo. Essas evoluçôes, ainda de acordo com os autores, variam de acordo com a qualidade das experiências por elas vivenciadas.

Desse modo, os processos de mediação, em uma abordagem sóciohistórica, corroboram com a compreensáo de que o processo de desenvolvimento cognitivo, social e afetivo é resultado da relaçáo homem e mundo, que acontece por meio do processo de mediação simbólica. Segundo Vygotsky (1997), o processo de mediação permite ao sujeito a internalização de açôes e conhecimentos construídos culturalmente por meio dos instrumentos e dos sistemas simbólicos, como, por exemplo, a linguagem.

Com base na fundamentação teórica de Vygotsky (1989), conclui-se que a mediaçáo é um elemento preponderante para o desenvolvimento holístico de pessoas com deficiência intelectual, mediante a conjuntura atual de nossa sociedade que tem centrado suas relaçóes nos usos das TDIC, pois, segundo Warschauer (2006) "a capacidade de acessar, adaptar e criar novo conhecimento por meio do uso das novas TDIC é decisiva para a inclusão social na época atual" (MONTARDO e PASSERINO, 2007, p. 06).

De acordo com os referenciais teóricos aqui apresentados, percebe-se que o uso das tecnologias pelas pessoas que apresentam deficiência intelectual colabora para a promoção da interação social, por desencadear o desenvolvimento integral destas pessoas, nos aspectos cognitivos, sociais e afetivos. Ao corroborar com esta premissa, Santarosa (2002, p.13) afirma que: "As ferramentas de comunicação e interconexão abrem um leque de oportunidades, principalmente para os sujeitos cujos padrões de aprendizagem não seguem os quadros típicos de desenvolvimento[...]”. Além disso, a interação social estimulada pelo uso dos computadores favorece a autonomia das pessoas com DI conforme observado nesta pesquisa.

$\mathrm{O}$ uso das TDIC por pessoas com deficiência intelectual promove a interação social, o que resulta no desenvolvimento integral dessas pessoas. Para Santarosa (2002), o uso dos recursos das TDIC em um contexto de mediação contribui para o desenvolvimento cognitivo, sócio-afetivo e de comunicação de pessoas com deficiência intelectual.

Basso (2000), ao discutir sobre a utilização das TDIC para o desenvolvimento cognitivo, afirma que o computador, quando utilizado como meio de interaçáo social, favorece o conflito cognitivo. Além disso, a sociedade, segundo Belloni (2001, p. 22) tem exigido um sujeito ativo, "dotado de competências técnicas múltiplas, habilidade de trabalho em equipe, capacidade de aprender e de adaptar-se a situaçôes novas".

Dessa forma, "as ferramentas de comunicação e interconexão abrem um leque de oportunidades, principalmente para os sujeitos cujos padróes de aprendizagem 
não seguem os quadros típicos de desenvolvimento [...]" (SANTAROSA, 2002, p. 13). dos.

Com base nesses referencias, procede-se a seguir a análise e discussão dos da-

\section{Análise e discussão dos dados - caminhos percorridos}

Dentre os dados da categoria Interação com TDIC, identificam-se 20 comportamentos que são organizados em níveis evolutivos e classificados como: elementares, intermediários e avançados, de acordo com as características de sua ocorrência.

Considera-se um comportamento elementar, quando o sujeito se mostra passivo ou não consegue planejar, organizar, regular ou tratar a informação, mesmo com a intervenção do mediador. $\mathrm{Ou}$, ainda, quando apresenta uma forte dependência do mediador ou quando demonstra ausência de reciprocidade (unilateralidade em suas interações sociais).

Um comportamento é considerado de nível intermediário quando o sujeito se mostra ativo em seu processo de ler ou escrever e consegue, por meio do apoio do mediador, I- planejar, organizar, regular, tratar informação em seu processo de leitura e escrita; II- perceber a inadequação de sua mensagem; III- identificar erros cometidos e superar pelo menos parcialmente as dificuldades encontradas e reagir à mediação formulando comentários, questôes ou dúvidas sobre o conteúdo ou sobre a forma da mensagem ou da mensagem do seu interlocutor (MV).

Por fim, o comportamento é considerado avançado quando o sujeito demonstra uma real autonomia em suas atividades de leitura e de escrita e espontaneamente, I- planeja, organiza, regula ou trata informação em seu processo de leitura e escrita; e/ ou II- verifica a adequaçáo de sua mensagem; e/ou III- identifica os erros cometidos e tenta corrigir e/ou IV- em um processo autônomo, supera pelo menos parcialmente as dificuldades encontradas e solicita ou confronta espontaneamente, em um processo caracterizado por reciprocidade, o ponto de vista do mediador, reservando para si a decisão final.

$\mathrm{Na}$ categoria Interação com TDIC identificam-se três comportamentos de nível elementar (Comportamento 1: acessa o email com a ajuda do mediador; Comportamento 2: acessa o blog com a ajuda do mediador; e, comportamento 3: utiliza a internet de forma equivocada) (Gráfico 1). 
Gráfico 1 - Interação com as TDIC: frequência dos comportamentos de nível elementar

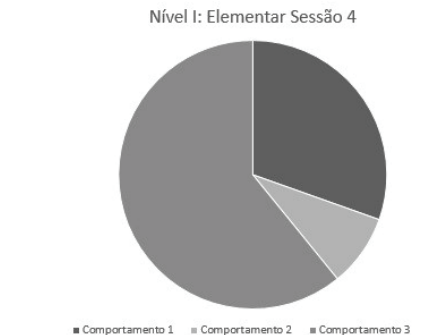

- Comportamento 1: acessa o email com a ajuda do mediador

- Comportamento 2: acessa o blog com a ajuda do mediador

- Comportamento 3: utiliza a internet de forma equivocada

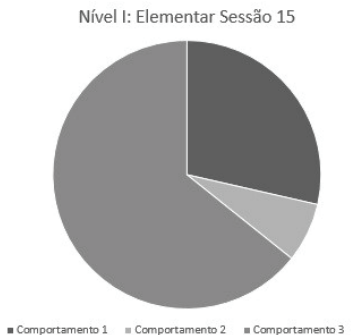

- Comportamento 1: acessa o email com a ajuda do mediador

- Comportamento 2: acessa o blog com a ajuda do mediador

- Comportamento 3: utiliza a internet de forma equivocada

Fonte: Relatório de Pesquisa PIBIC - $2015^{2}$

No gráfico 1 observa-se que, ocorre uma diminuição significativa $(t=<0,01)$ dos comportamentos de nível elementar, da sessão 4 para a sessão 15 . Ao compararmos a sessão 4 com a sessão 15 o comportamento 1 (Acessa o email com a ajuda do mediador) passou de uma frequência de 7 acessos ao email com a ajuda do mediador para 4 acessos com a ajuda do mediador; o comportamento 2 (Acessa o blog com a ajuda do mediador) diminuiu a frequência de 2 acessos ao blog com a ajuda do mediador para 1 acesso com ajuda; e o comportamento 3 (Utiliza a internet de forma equivocada) diminuiu a frequência de 14 utilizaçóes equivocadas da internet para 9 utilizaçôes equivocadas. Os dados das frequências dos comportamentos dos alunos com DI revelam que a mediação dos MV se mostrou positiva, pois os sujeitos com DI demonstram autonomia ao acessar o email e o blog e demonstram menos erros ao utilizar a internet.

Dessa forma, o blog em nossa pesquisa revela-se como um recurso favorável. Visto que seu uso desperta o interesse dos participantes com deficiência intelectual, na medida em que os motivava a explorar, a pesquisar, a descrever e a refletir. No desenvolvimento do blog, o MV media à formalização do seu uso para que esses participantes com DI possam, gradualmente, dar significado ao que está sendo aprendido.

Os comportamentos elementares podem ser evidenciados no diálogo abaixo na sessão 4 (SE4):

MV: Qual o primeiro procedimento, a primeira coisa que vc tem que fazer para chegar nesse blog?

P1: o email.

MV: lembra do teu email?

P1: um pouco. 
MV: Um pouco? O quê que tu lembras desse pouco? (P1 fala seu nome completo). (MV repete o nome de P1 interrogando)

MV:Digita aí.(P1 digita no campo login do gmail)

MV: Davi Vieira Passos, pronto e o quê mais?

P1: ponto com

MV: ponto com? Num é um email?

P1: gmail.

MV: antes do gmail tem uma coisinha que tá aí no meio, o que é?

P1 digita @gmail

MV fala: gmail...

P1 fala ponto com e digita: com

Todos os passos de P1 são mediados pelo MV, no intuito de fazê-lo lembrar dos procedimentos iniciais para acessar o blog. O MV estimula P1, com o cuidado de não antecipar as respostas, e sim apontar dicas verbais para que o mesmo desenvolva com autonomia o acesso ao blog. Os dados revelam que a mediação é um fator primordial para gerar autonomia nos sujeitos com DI quanto ao uso das TDIC.

Esses dados refletem, também, que as estratégias de mediação junto as TDIC envolve o aluno numa realidade que, segundo Almeida Filho (1999), vai além da sala de aula, pois possibilita um aprendizado contextualizado, que parte do interesse do aluno. Dessa forma, o papel do mediador se mostra fundamental.

Considera-se, assim, que as pessoas sejam, ao mesmo tempo, sujeitos individuais e, como tais, possuem diferentes habilidades de aprendizagem, diferentes estratégias de tratamento da informaçáo, como também sujeitos coletivos que vivenciam constantes processos de interações sociais e culturais. O ambiente de aprendizagem adequado e, naturalmente, a açáo mediadora do professor, nessa perspectiva, são elementos que podem favorecer o processo de construção do conhecimento (COSTA e PAIM, 2004, p. 21).

A mediação é uma ação importante para o desenvolvimento da díade ensino e aprendizagem de pessoas com deficiência intelectual. Essas pessoas podem demonstrar, em situaçóes de aprendizagem mediada, habilidades cognitivas e capacidade de fazer a transferência do conhecimento adquirido para outros contextos (FEUERSTEIN, 1997; FEUERSTEIN, RAND, HOFFMAN, 1979; FONSECA, 1998; GOMES; POULIN; FIGUEIREDO, 2010). De acordo com Feuerstein (1997), todos os aprendizes são sujeitos cognoscentes, porém a aprendizagem só se torna significativa a todos se o mediador intervir além da transmissão de conhecimentos. 
Gomes (2002) coloca que, para Feuerstein

todo indivíduo que apresenta retardo mental pode ter sua inteligência modificada - o retardo mental não é próprio da estrutura cognitiva do indivíduo nem uma qualidade irreversível. Deve-se eliminar a condição de retardo, ou pelo menos diminuí-la, bem como diminuir as limitaçóes que o retardo cria, através de uma aprendizagem mediada. Essa postura modifica a educação: da educação do 'retardo mental' para uma educação à normalidade. (GOMES, 2002, p. 156).

Nas primeiras sessões, os participantes da pesquisa não tinham autonomia para fazer uso das TDIC, entretanto, com a mediaçáo, eles passaram a pesquisar e incluir novos elementos em suas postagens. Essa evidência é ilustrada pelo diálogo abaixo durante a sessão 9 (SE9) na mediação de MV com um dos participantes da pesquisa - P1, que opta nesse dia em fazer uma homenagem a sua tia que fazia aniversário:

MV: Você vai colocar alguma imagem?

P1: vou

MV: quer pesquisar? A sua tia gosta de quê?

P1: rosas

MV: rosas? Você vai colocar uma imagem de rosas para ela? (P1 abre uma nova aba. Carrega a página inicial de pesquisa do Google. P1 digita na barra de endereços a palavra 'imagem).

MV: que palavra você digitou?

P1: imagem.

MV: Vamos ler a palavra? (P1 lê a palavra I-M-A-G-E-N-I-S, não I-M-A-G-E-M) tem o que no final? (MV aponta a palavra na tela de busca do Google)

P1: ah! (E digita 'imagens)'

MV: tu acha que cor de rosas ela gosta?

P1: rosas amarelas.

MV: imagens de quê tu tem que botar?(Carrega a página de pesquisa para imagem)

MV: mas tu tem que colocar o tema da imagem aqui.(P1 clica em voltar. Carrega a página de pesquisa do Google. P1 clica na janela de pesquisa. P1 digita rosas vermelhas e tecla enter. Carrega a página de pesquisa para rosas vermelhas).

Observou-se que os comportamentos da categoria Interação com TDIC concentram-se no nível intermediário, totalizando uma frequência de 171 comporta- 
mentos em detrimento a 154 do avançado e somente 52 do elementar. Neste nível são identificados sete comportamentos. Em termos percentuais, ocorre uma diminuição no nível intermediário de 60,16\% na sessão 4 para 45,66\% na sessão 15.

Dois comportamentos de nível intermediário diminuíram significativamente: o comportamento 3 (utiliza as ferramentas do blog após a mediação), de 12 para 2; e o comportamento 6 (utiliza as ferramentas do e-mail com a mediação), de 23 para 0 (Gráfico 2).

Gráfico 2 - Interação com as TDIC: frequência dos comportamentos nível intermediário

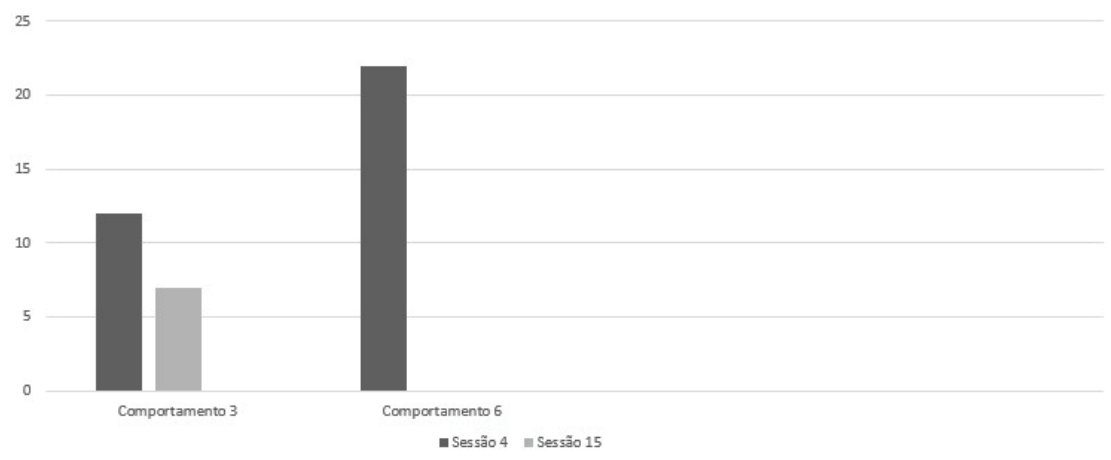

Fonte: Relatório de Pesquisa PIBIC - 2015

O gráfico 2 reforça o papel do mediador no favorecimento das interaçóes dos sujeitos com DI com as TDIC, que passa a utilizar as ferramentas do blog e do e-mail com autonomia. O diálogo da SE9 abaixo evidencia a manifestação desses comportamentos do nível intermediário:

MV: olha aí é adicionar legenda, tu pode escrever alguma coisa embaixo, alguma dedicatória, tu quer escrever?(P1 clica no campo da legenda e responde: quero, uma rosa. Tem uma pausa)

MV: é isso mesmo?(P1 diz: uma rosa para outra rosa e digita: uma rosa para outra rosa)

MV: Muito lindo.

Marcuschi e Xavier (2005) afirmam que os blogs, os e-mails, assim como as redes sociais, podem contribuir para o ensino, pois se configuram como um ambiente de conversação, no qual os interlocutores são levados a produzirem respostas imediatas e elaborarem seus próprios argumentos ainda que informais. Todas essas possibilidades podem auxiliar no desenvolvimento do estudante mais do que se imagina.

Vale ressaltar que, o estudo da produção escrita de pessoas com deficiência intelectual indica que embora elas sejam capazes de produzirem escrita alfabética, essa 
escrita é bastante limitada quanto à criação de ideias, se caracterizando algumas vezes por uma superposiçẫo de frases ou pela reprodução de um modelo escolar de texto (FIGUEIREDO e CRISPIM, 2005). Dessa forma, parece que a limitação no texto desses sujeitos se traduz principalmente no que se refere à criação de ideias, visto que os erros de ortografia cometidos sáo semelhantes àqueles cometidos pelos principiantes na escrita alfabética (GOMES, 2006). E o diálogo acima revela uma autonomia na escrita do sujeito com DI com o desenvolvimento de seu potencial criativo.

Retomando as análises da manifestação dos comportamentos, verifica-se que quanto ao nível avançado, observa-se que há aumento nos comportamentos considerados de nível avançado de $20,33 \%$ na $4^{\text {a }}$ para $43,30 \%$ na $15^{\text {a }}$ sessão. Os sujeitos com DI demonstraram 10 comportamentos considerados de nível avançado. Respondem pelo aumento significativo desse nível evolutivo os comportamentos a seguir: 1) "Acessa o e-mail sem recorrer à ajuda do mediador", que passou de 2 frequência nesse comportamento para 10 e 9) "Utiliza a internet adequadamente sem a mediação", que passou de 7 para 24 manifestaçóes nesse item (Gráfico 3).

\section{Gráfico 3 - Interação com as TDIC: frequência dos comportamentos de nível avançado}

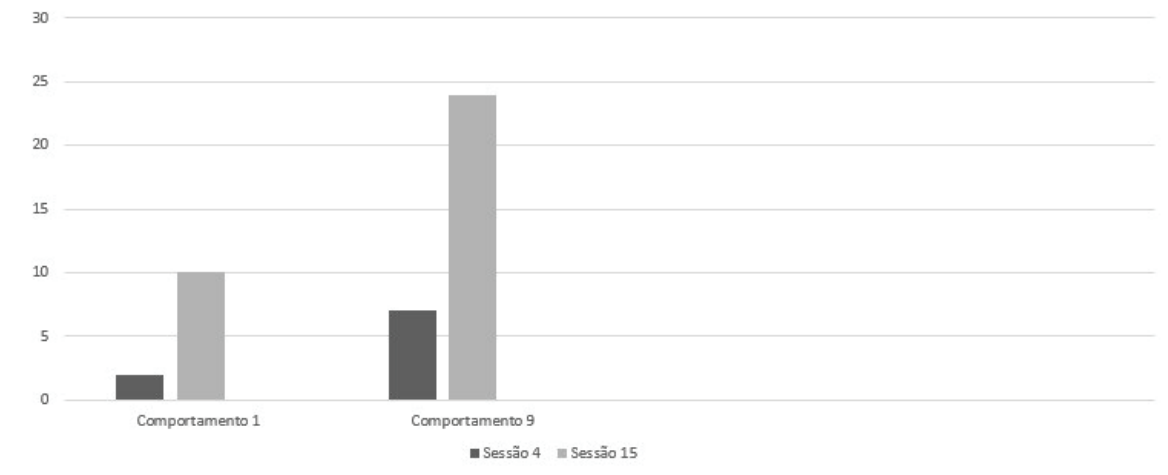

Fonte: Relatório de Pesquisa PIBIC - 2015

Observa-se com o gráfico 3 que a familiaridade com o meio digital proporciona maior autonomia aos participantes com deficiência intelectual. Visto que eles são capazes de desenvolver aprendizagens relacionadas ao manuseio das tecnologias digitais da comunicação e informação, como, por exemplo, o acesso ao e-mail e ao blog pessoal. Esse resultado sugere, também, que pessoas com deficiência intelectual são capazes de se apropriar de conhecimentos relativos ao desenvolvimento da linguagem escrita sob a influência da tecnologia digital em contextos de aprendizagem mediada.

Neste estudo, constatou-se, que, a interação com as Tecnologias Digitais de Informação e Comunicação - TDIC contribui para a evoluçáo escrita dos cincos participantes com DI. Todos eles evoluíram quanto à capacidade de utilizar a internet como recurso para ampliar as informaçóes contidas em seus blogs, bem como usar a internet como estratégia para redigir e enriquecer seus textos. 


\section{Considerações finais}

As TDIC estão presentes no cotidiano de nossas escolas, nos lares, no mercado de trabalho, e vem transformando as práticas pedagógicas. Dessa forma, o blog é uma das ferramentas digitais que podem ser utilizadas para desenvolver a competência escrita através das postagens, com a produção de textos espontâneos.

Ao observar os dados supracitados, percebe-se que a mediação durante as interações com as TDIC se expressa como significativa para a construção da produção escrita, por possibilitar aos participantes com deficiência intelectual momentos de discussão e ampliação de ideias nessa produção. $\mathrm{O}$ corolário dessa afirmação é que esse entendimento pode promover o desenvolvimento de competências futuras nesse alunado compreendendo-os como sujeitos cognoscitivos.

Os resultados encontrados permitem destacar aspectos importantes que possibilitam uma melhor compreensão acerca da influência da mediação em contexto digital. Os alunos com deficiência intelectual realizaram alteraçôes em seus textos mediante estratégias de mediação dos mediadores voluntários, o que sugere que essas estratégias se apresentaram como instrumento importante para a produçáo escrita desses alunos, em contexto digital.

A decorrência de se aceitar essa afirmação como verdadeira é que, aos que se envolvem com o processo de ensino e aprendizagem de pessoas com deficiência intelectual, cabe estabelecer coletivamente açóes mediadas, para que em parceira professores e alunos possam ampliar, modificar e construir significados.

Entretanto, evidencia-se que a mediação não pode ser descontextualizada e sem objetividade. Isto porque pessoas com DI se beneficiam das tecnologias digitais de informação e comunicação e demonstram competência para utilizar os recursos disponíveis no meio digital, quando suas açôes são mediadas de forma clara, contextualizada, objetiva e adequada.

\section{Referências}

ALMEIDA FILHO, J. C. P. O professor de língua estrangeira em formaçáo. Campinas: Pontes, 1999.

BASSO, C. M. Algumas reflexôes sobre o ensino mediado por computador. Revista Linguagem e Cidadania, ed. 004, dez. 2000. Disponível em: <http://www.ufsm.br/lec/02_00/Cintia-L\&C4.htm>. Acesso em: 26 jun. 2015.

BELLONI, M. L. O que é Mídia-Educaçáo. Campinas: Autores Associados, 2001.

CEREJA, W. R; MAGALHÂES, T. C. Português: linguagens. Vol. I. 6a ed. reform. - São Paulo: Atual, 2008.

COSTA, J. W.; PAIM, I. Informação e conhecimento no processo educativo. In: COSTA, J. W. da; OLIVEIRA, M. A. M. (Orgs.). Novas linguagens e novas tecnologias: Educação e sociabilidade. Petrópolis, RJ: Vozes, 2004.

DELVILLE, J.; MERCIER, M.; MATTYS, M. Promoçấo da saúde na educação especializada. In: LEPOTFROMENT, C. (Org.). Educaçáo Especializada: pesquisa e indicaçóes para a açáo. Bauru: EDUSC, 1999. p. 193-209.

FEUERSTEIN, R; RAND, Y.; HOFFMAN, M. The dynamic Assessment of Retardet Performance: The Learning Assessment Device, Theory, Instruments, and Techniques. Glenview, Illinois: Scott, Foresman \& Company, 1979.

FEUERSTEIN, R. Teoria de la Modificabilidad Cognitiva Estructural. Madrid: Editora Bruno, 1997. 
FIGUEIREDO, R. V. de; FERNANDES, A. C. A importância da mediação pedagógica na apropriação de estratégias de escrita por alunos com deficiência intelectual. In: Anais $1^{\circ}$ Encontro de pesquisa educacional Norte e Nordeste, João Pessoa. 2009.

FIGUEIREDO, R. V. de; FERNANDES, A. C. Relatório Técnico de Pesquisa: Projeto Gestão da Aprendizagem na Diversidade. Universidade Federal do Ceará - CAPES. 2008.

FIGUEIREDO, R. V. de; FERNANDES, A. C.; CRISPIM, R. A importância da mediação pedagógica no desenvolvimento dos processos metacognitivos relacionados a leitura e a escrita em alunos com deficiência mental. In: Anais do $\mathbf{1 2}^{\circ}$ Encontro de pesquisa Norte e Nordeste-EPENN, Belém (PA), 2005.

FONSECA, V. da. Aprender a aprender: a educabilidade cognitiva. Porto Alegre: Artmed, 1998.

FRIEND, M.; BURSUCK, W. Inclusind Students with Special Needs: A practical guide for Classroom Teachers. Boston: Pearson, 1999

GIROTO, C. R. M.; POKER, R. B.; OMOTE, S. (Orgs.). As tecnologias nas práticas pedagógicas inclusivas. Marília: Oficina Universitária; São Paulo: Cultura Acadêmica, 2012.

GOMES, A. L. L. "Como subir nas tranças que a bruxa cortou”? Produção textual de alunos com síndrome de Down. 290f., 2006. Tese de Doutorado. Universidade Federal do Ceará - Programa de Pós-Graduação em Educação Brasileira, 2006.

GOMES, A. L. L.; POULIN, J. R.; FIGUEIREDO, R. V. de. Atendimento Educacional Especializado do aluno com deficiência intelectual. São Paulo: Moderna, 2010 (Cotidiano escolar: ação docente).

GOMES, C. M. A. Feuerstein e a construçáo mediada do conhecimento. Porto Alegre: Artmed, 2002.

KOMESU, F. C. Blogs e as práticas de escrita sobre si na internet. In: MARCUSCHI, L. A.; XAVIER. A. C. (Orgs.) Hipertexto e gêneros digitais: novas formas de construção de sentido. Rio de Janeiro: Lucerna, 2005.

MARCUSCHI, L. A.; XAVIER, A. C. (Orgs.). Hipertexto e gêneros digitais: novas formas de construçấo do sentido. - 2a ed. Rio de Janeiro: Lucerna, pp. 13 - 67, 2005.

MARCUSCHI, L. A.; XAVIER, A. C. (Orgs.). Gêneros textuais emergentes no contexto da tecnologia digital. In: MARCUSCHI, L. A.; XAVIER, A. C. (Orgs.) Hipertexto e Gêneros Digitais: novas formas de construção do sentido. 3. ed. Sáo Paulo: Cortez, 2010. p. 15 - 80.

MONTARDO, S. P.; PASSERINO, L. Espelhos quebrados no ciberespaço: apontamentos iniciais para proposta de modelo de ARS em blogs de PNE. In: Anais IX Seminário Internacional da Comunicaçáo: Simulacros e (Dis) simulaçóes na Sociedade Hiper-espetacular, 2007, Porto Alegre. IX Seminário Internacional da Comunicação. Porto Alegre: Edipucrs, 2007. v. 1. p. 31-31.

MURANO, E. O texto na era digital. Revista Língua Portuguesa. São Paulo: Editora Segmento, pp. 28 - 33. Ano 5, no 64, fevereiro de 2011.

OMS. International Classification of Functioning, Disability and Health - version for children and youth. Geneva: Organização Mundial de Saúde, 2007.)

PRIMO, A. F. T.; RECUERO, R. da C. Hipertexto Cooperativo: Uma Análise da Escrita Coletiva a partir dos Blogs e da Wikipédia. Revista da FAMECOS, n. 23, p. 54-63, Dez. 2003.

ROCHA. S. R. M, ALVES, J. G. \& NEVES, H. S. F. das. Indivíduos com deficiência e mediação em leitura: reconstruindo identidades. In: Revista de Educaçáo Especial/Universidade Federal de Santa Maria/Centro de Educação, Departamento de Educação Especial. - N 24, v. 29, Santa Maria, 2004.

SANCHES-FERREIRA, M; LOPES-DOS-SANTOS, P; SANTOS, M. A. A desconstruçăo do conceito de Deficiência Mental e a construção do conceito de Incapacidade Intelectual: de uma perspectiva estática a uma perspectiva dinâmica da funcionalidade. Rev. Bras. Ed. Esp., Marília, v. 18, n. 4, p. 553-568, Out.-Dez., 2012.

SANTAROSA, L. M. C. Cooperação Na Web Entre PNEE: construindo conhecimento no Núcleo de Informática na Educação Especial da UFRGS. Fortaleza: Anais do Congresso Ibero-americano de Informática na Educação Especial - III CIIEE- SEESP/MEC. Publicado em meio digital CD, pp.64-79, ago., 2002.

SILVA, S. P.; PESSANHA, A. P. B. A produçáo textual e as novas tecnologias: o uso de blogs para a escrita colaborativa. Rio de Janeiro: Revista Escrita, p. 01 - 14, nº 15, 2012.

VYGOTSKY, L. S. Obras Completas: fundamentos da defectologia. Tomo V. Trad. Lic. Ma. del Carmen Ponce Fernández. Ciudad de La Habana: Editorial Pueblo y Educación, 1989.

VYGOTSKY, L. S.. Pensée et langage (3ème éd., F. Sève, trad.). Paris: La Dispute, 1997 (Original publié 1934). WARSCHAUER, M. Tecnologia e inclusão social: A exclusão digital em debate. São Paulo: Editora Senac, 2006. 


\section{Notas}

${ }^{1}$ Metacognição diz respeito ao ato de conhecer e controlar a construção do seu próprio conhecimento.

${ }^{2}$ A interação entre alunos com Deficiência Intelectual e mediadores voluntários: A influência da mediação sobre os aspectos semânticos da produção escrita em contexto de comunicação digital (PIBIC/2015).

\section{Correspondência}

Flávia Roldan Viana - Universidade Federal do Rio Grande do Norte, Centro de Educação. Travessa Senador Salgado Filho, Lagoa Nova. CEP: 59064-741. Natal, Rio Grande do Norte. Brasil.

E-mail: soeuflarv@yahoo.com.br - adrianalimaverde@ufc.br

Recebido em 22 de abril de 2016

Aprovado em 10 de outubro de 2016 
